\title{
Elevated telomere-telomere recombination in WRN-deficient, telomere dysfunctional cells promotes escape from senescence and engagement of the ALT pathway
}

\author{
Purnima R. Laud, ${ }^{1,5}$ Asha S. Multani, ${ }^{1,5}$ Susan M. Bailey, ${ }^{2,5}$ Ling Wu ${ }^{1}{ }^{1}$ Jin $\mathrm{Ma}^{,}{ }^{1}$ Charles Kingsley, ${ }^{1}$ \\ Michel Lebel, ${ }^{3}$ Sen Pathak, ${ }^{1}$ Ronald A. DePinho, ${ }^{4,7}$ and Sandy Chang ${ }^{1,6}$ \\ ${ }^{1}$ Department of Molecular Genetics, University of Texas, The M.D. Anderson Cancer Center, Houston, Texas 77030, USA, \\ ${ }^{2}$ Department of Environmental and Radiological Health Sciences, Colorado State University, Fort Collins, Colorado 80523, \\ USA; ${ }^{3}$ Centre de Recherche en Cancérologie de 1'Université Laval, Hôpital Hôtel-Dieu de Québec, Québec, Canada G1R 2J6; \\ ${ }^{4}$ Department of Medical Oncology and Center for Applied Cancer Science, Dana-Farber Cancer Institute and Departments of \\ Medicine and Genetics, Harvard Medical School, Boston, Massachusetts 02115, USA
}

\begin{abstract}
Werner Syndrome (WS) is characterized by premature aging, genomic instability, and cancer. The combined impact of WRN helicase deficiency and limiting telomere reserves is central to disease pathogenesis. Here, we report that cells doubly deficient for telomerase and WRN helicase show chromosomal aberrations and elevated recombination rates between telomeres of sister chromatids. Somatic reconstitution of WRN function, but not a WRN helicase-deficient mutant, abolished telomere sister chromatid exchange (T-SCE), indicating that WRN normally represses T-SCEs. Elevated T-SCE was associated with greater immortalization potential and resultant tumors maintained telomeres via the alternative lengthening of telomere (ALT) pathway. We propose that the increased incidence of chromosomal instability and cancer in WS relates in part to aberrant recombinations between sister chromatids at telomeres, which facilitates the activation of ALT and engenders cancer-relevant chromosomal aberrations and tumor formation.
\end{abstract}

[Keywords: Werner; alternative lengthening of telomeres; cancer; escape from senescence; telomeres]

Supplemental material is available at http://genesdev.org.

Received April 5, 2005; revised version accepted September 6, 2005.

Werner Syndrome (WS) is a rare autosomal recessive disorder characterized by premature onset of age-related pathologies, including hair graying, alopecia, cataracts, osteoporosis, type II diabetes, cardiovascular disorders, and mesenchymal neoplasms (for review, see Martin and Oshima 2000). WS fibroblasts senesce prematurely in culture (Faragher et al. 1993) and display increased chromosome instability including chromosomal translocations and deletions (Salk et al. 1981; Melcher et al. 2000). The gene mutated in WS, WRN, encodes a highly conserved DNA helicase of the RecQ family that appears to function in many aspects of DNA metabolism and chromosome stability (for review, see Hickson 2003). Deletion

\footnotetext{
${ }^{5}$ These authors contributed equally to this work.

Corresponding authors.

${ }^{6} \mathrm{E}-\mathrm{MAIL}$ schang@mdanderson.org; FAX (713) 834-6319.

${ }^{7}$ E-MAIL ron_depinho@dfci.harvard.edu; FAX (617) 632-6069.

Article and publication are at http://www.genesdev.org/cgi/doi/10.1101/ gad.1321305.
}

of the yeast homolog of WRN, SGS1, leads to aberrant recombination between repeated homologous sequences (Yamagata et al. 1998; Myung et al. 2001), suggesting that a normal role of WRN is suppression of aberrant recombinations which may contribute to the increased genomic instability observed in WS cells (Prince et al. 2001).

Increasing evidence supports the hypothesis that WRN plays a direct role in telomere maintenance. Telomeres are specialized nucleoprotein structures consisting of G-rich repetitive sequences that cap the ends of eukaryotic chromosomes and are crucial for the maintenance of chromosomal stability (for review, see Smogorzewska and de Lange 2004). Telomeres are maintained by the enzyme telomerase, which consists of an essential telomerase RNA (Terc) that serves as a template for the addition of telomere repeats, and a protein component, the telomerase reverse transcriptase catalytic subunit (Tert). Accelerated loss of telomere reserves and activation of cellular checkpoints appear integral to the de- 
creased replicative potential observed in WS, as evidenced by the capacity of enforced TERT expression to impart unlimited replicative potential (Wyllie et al. 2000). However, it is possible that TERT overexpression may activate additional proliferative pathways other than those linked to telomere maintenance (Blasco 2002).

A central role of dysfunctional telomeres in driving the WS phenotypes has received genetic support from mice doubly deficient for telomerase and WRN. In this model, while Wrn deficiency alone had no cellular or tissue phenotypes (Lombard et al. 2000), successive generational matings of $\mathrm{mTerc}^{-/-} \mathrm{Wrn}^{+/-}$mice and ensuing telomere dysfunction produced symptoms and pathologies with striking similarities to the human disease, including a full spectrum of premature aging phenotypes and elevated incidence of mesenchymal cancers (S. Chang et al. 2004; Du et al. 2004). On the cellular level, late-generation $\mathrm{mTerc}^{-1-} \mathrm{Wrn}^{-/-}$mouse embryo fibroblasts (MEFs) exhibited profound premature replicative senescence similar to that seen in human WS fibroblasts (S. Chang et al. 2004; Du et al. 2004). These murine observations, together with those derived from the study of human WS cells, strongly support the hypothesis that the WRN deficiency exerts its complex and diverse pathophysiological consequences primarily through accelerated telomere erosion and associated dysfunction.

WRN functionally interacts with a number of proteins involved in telomere length maintenance, indicating that it may influence telomerase access to the 3' G-rich overhang by unwinding the t-loop structure adopted by mammalian telomeres (Opresko et al. 2004). WRN also localizes to telomeres of telomerase-deficient cells that maintain telomeres via the alternative lengthening of telomeres (ALT) mechanism (Johnson et al. 2001; Opresko et al. 2004). In addition, WRN is required for the efficient replication of lagging strand telomeric DNA, suggesting that WRN may function during telomere replication by resolving aberrant DNA structures that block replication forks (Crabbe et al. 2004).

In this study, we utilized genetically defined mouse cells to understand the impact of WRN deficiency on telomere maintenance, chromosomal stability, cellular mortality, and tumorigenesis. Our results indicate that the increased incidence of chromosomal instability and cancer in WS may be due to aberrant recombinations between sister chromatids specifically at telomeres, which may promote the activation of the ALT pathway and lead to chromosomal instability during tumorigenesis.

\section{Results}

Generation 5 (G5) $\mathrm{mTerc}^{-/-} \mathrm{Wrn}^{-/-}$MEFs escape cellular senescence and spontaneously immortalize

The profound senescence phenotype exhibited by G5 $\mathrm{mTerc}^{-/-} \mathrm{Wrn}^{-1-}$ MEFs prevented the generation of immortalized cell lines via the standard 3T3 protocol, whereas generation 3 (G3) $\mathrm{mTerc}^{-/-} \mathrm{Wrn}^{-/-}$and wild- type MEFs with adequate telomere reserves readily generated immortalized 3T3 cultures (S. Chang et al. 2004). To further assess the immortalization potential of lategeneration $\mathrm{mTerc}^{-/-} \mathrm{Wrn}^{-/-}$cells, we adopted an alternative approach that monitored spontaneous focus formation in senescent MEF cultures maintained by weekly media changes. After $\sim 2$ mo in culture, several foci emerged among $8 \times 10^{6}$ senescent G5 $\mathrm{mTerc}^{-/-} \mathrm{Wrn}^{-1-}$ MEFs at a frequency of $\sim 1.4 \times 10^{-5}$.

Under identical culture conditions, foci were not detected in senescent cultures of $\sim 5 \times 10^{7} \mathrm{G} 5 \mathrm{mTerc}^{-/-}$ $\mathrm{Wrn}^{+/+}$and $\sim 2.5 \times 10^{7} \mathrm{G} 5 \mathrm{mTerc}^{-/-} \mathrm{Wrn}^{+/-} \mathrm{MEFs}$. To assess the growth properties of these cells, six independently derived foci originating from five different G5 $\mathrm{mTerc}^{-/-} \mathrm{Wrn}^{-/-}$embryos were subcloned, expanded, and subjected to serial passages (Fig. 1A). All clones displayed robust growth curves over 100 population doublings (PDs), characteristic of immortalized cells. These observations suggest that Wrn deficiency can facilitate escape from senescence and are permissive for the sustained growth of $\mathrm{mTerc}^{-/-}$cultures with significant telomere dysfunction.

To gain insight into the molecular basis of immortalization, we assayed the integrity of the $\mathrm{p} 19^{\mathrm{Arf}}-\mathrm{p} 53$ pathway in early passage and immortal G5 $\mathrm{mTerc}^{-1-} \mathrm{Wrn}^{-/-}$ cultures. Inactivation of this pathway is an obligate event in the immortalization of murine cells (for review, see Ben-Porath and Weinberg 2004). Although early passage cultures revealed the typical low p53 levels (Liu et al. 2004), the functional integrity of p53 is evidenced by ionizing radiation (IR)-induced induction of the p53-responsive target, $\mathrm{p} 21$. In contrast, all six independently derived G5 $\mathrm{mTerc}^{-/-} \mathrm{Wrn}^{-1-}$ immortal cultures showed moderate p53 expression yet failed to exhibit IR-induced p21 induction. In addition, these immortal cultures expressed high p19 ${ }^{\text {Arf }}$ levels (Fig. 1B), the latter consistent with loss of p53 feedback inhibition (Quelle et al. 1995; Kamijo et al. 1997). These results indicate that G5 $\mathrm{mTerc}^{-/-} \mathrm{Wrn}^{-/-}$cell lines experienced disruption of the p19 ${ }^{\text {Arf }}$-p53 axis upon immortalization.

Telomere status and formation of telomere double minute chromosomes in immortalized G5 $\mathrm{mTerc}^{-/-}$ $\mathrm{Wrn}^{-1-}$ clones

The critical roles of telomeres and the WRN helicase in the maintenance of genome integrity (S. Chang et al. 2004) and the reported increasing chromosomal instability in human cultures emerging from telomere-based replicative senescence (Counter et al. 1992; Romanov et al. 2001) prompted a detailed cytogenetic analysis of parental and immortal cultures. In contrast to the paucity of chromosomal aberrations in early passage parental cultures, all six immortalized G5 $\mathrm{mTerc}^{-/-} \mathrm{Wrn}^{-/-}$cell lines displayed numerous chromosomal aberrations typified by homologous p-p arm (Robertsonian-like) fusions, unstable $\mathrm{q}-\mathrm{q}$ arm fusions (generating dicentric chromosomes), and chromatid breaks (Fig. 1C). Spectral karyotyping (SKY) revealed multiple nonreciprocal translocations (NRTs) (Fig. 1D). Consistent with the ability of 
Laud et al.

A

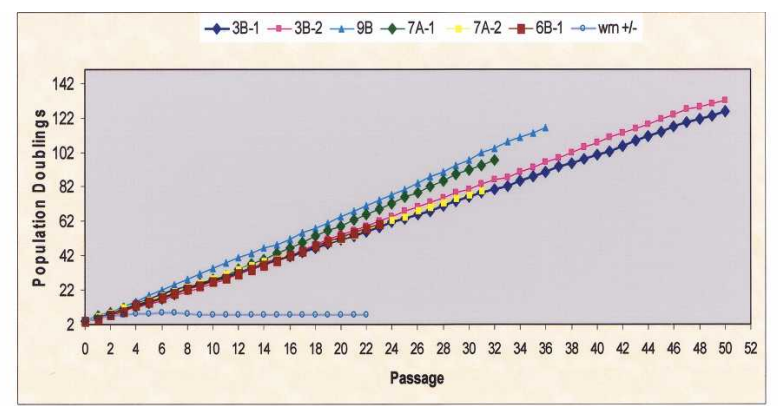

C

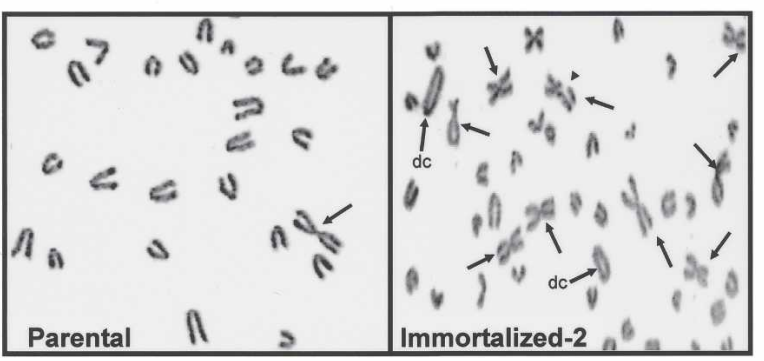

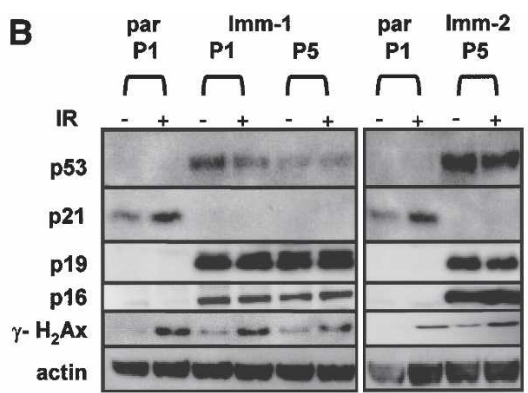

D

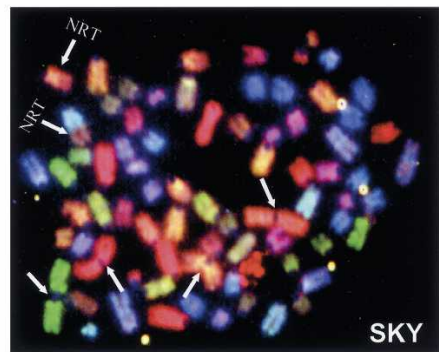

E

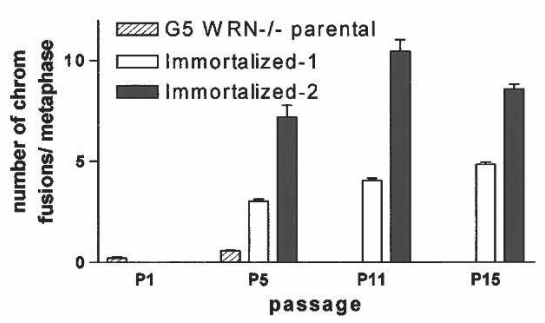

Figure 1. G5 mTerc ${ }^{-/-} \mathrm{Wrn}^{-/-} \mathrm{MEFs}$ spontaneously immortalize and exhibit chromosomal aberrations. (A) Serial NIH $3 \mathrm{~T} 3$ assays of six independently derived G5 $\mathrm{mTerc}^{-/-} \mathrm{Wrn}^{-/-}$cell lines passaged over 100 PDs. (B) Western blot analysis of p53, p21, p19, p16, and $\gamma \mathrm{H} 2 \mathrm{AX}$ expression in passage 1 (P1) to P5 parental (par), and immortalized clones 1 and 2 with (+) or without (-) 5 Gy $\gamma$-radiation (IR) treatment. Actin was used as loading control. $(C)$ Chromosomal aberrations in P4 parental and immortalized clones. (Arrows) p-p arm chromosomal fusions; (arrowhead) chromatid break; (dc) dicentric chromosome. (D) Spectral karyotyping (SKY) of representative immortalized clone. (Arrow) p-p arm chromosomal fusions; (NRT) nonreciprocal translocations. (E) Quantitation of the number of chromosomal fusions per metaphase in the indicated cell lines as a function of increased passages in vitro.

dicentric chromosomes to generate unstable anaphase bridges (for review, see Maser and DePinho 2002), anaphase bridges were detected in all immortalized cell lines but were not evident in respective parental cultures (Fig. 2A,B; data not shown). In line with these observed chromosome breakage events, $\gamma \mathrm{H} 2 \mathrm{AX}$ signal was readily detected in the immortal G5 $\mathrm{mTerc}^{-/-} \mathrm{Wrn}^{-/-}$cell lines and formed characteristic DNA damage-induced foci (Fig. 1B; data not shown). Together, these patterns prompt speculation that randomly broken anaphase bridges generate highly recombinogenic chromosomal intermediates that give rise to the complex cytogenetic profiles of the immortalized G5 mTerc ${ }^{-/-} \mathrm{Wrn}^{-/-}$cell lines.

The known physical interactions between telomeres and WRN (Crabbe et al. 2004; Opresko et al. 2004) and the documented chromosomal fusions in the immortal G5 mTerc ${ }^{-/-} \mathrm{Wrn}^{-/-}$cell lines prompted a detailed analysis of their telomere status. Fluorescence in situ hybridization (FISH) with a peptide-nucleic acid (PNA)-telomere probe revealed that all fused chromosomes lacked detectable telomeric signals at their sites of fusion, suggesting that they are a byproduct of significant telomere erosion or deletion (Figs. 2C, 3B,C). Correspondingly, telomeric restriction fragment (TRF) analyses documented a progressive decline in telomere length upon limited passages in vitro (Fig. 2D; Supplementary Fig. S1) and this decline tracked well with a steady increase in the number of fused chromosomes (Fig. 1E). Furthermore, mTerc transduction of these cultures revealed that, in contrast to vector-transduced controls, reconstituted telomerase activity resulted in stabilized telomere lengths over several passages in culture (Supplementary Fig. S1). Finally, as loss of the G-rich overhang can lead to telomeric fusions, we documented an absence of significant perturbations in the G-rich single-stranded telomeric overhangs, as evidenced by robust hybridization with a C-strand oligonucleotide probe to telomeric termini (Fig. 2D). These results suggest that telomere length maintenance mechanisms have not been overtly activated in serially passaged immortalized G5 $\mathrm{mTerc}^{-/-}$ 
A

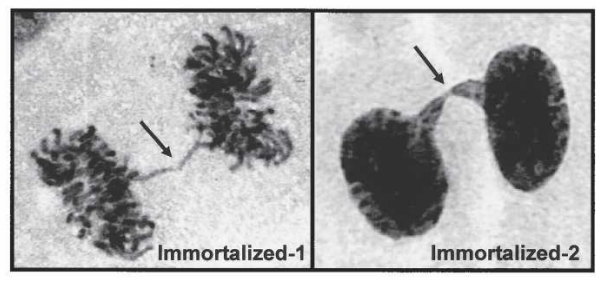

C

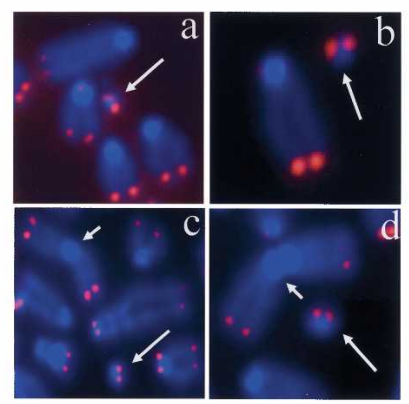

B

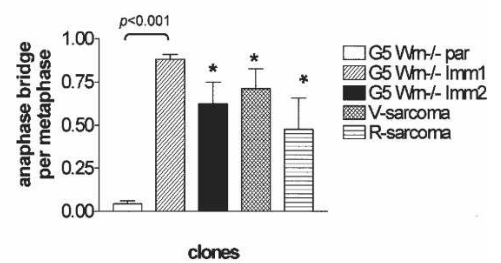

D

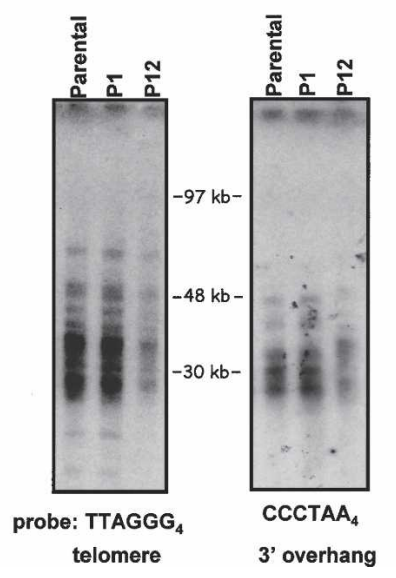

Figure 2. Characterization of telomere structure and TDMs in G5 $\mathrm{mTerc}^{-1-} \mathrm{Wrn}^{-1-}$ immortalized clones. (A) Anaphase bridge formation (arrows) in immortalized clones. $(B)$ Quantification of number of anaphase bridges per metaphase in cells of indicated genotypes. Error bars represent standard error of the mean (SEM). Asterisk ( $\left.{ }^{\star}\right)$ indicates a $p$ value of $<0.001$ (Student's $t$-test). (C) Metaphase chromosomes isolated from representative immortalized clones were stained by DAPI (blue) and telomeric DNA was detected by FISH with rhodamine-conjugated (CCCTAA) ${ }_{3}$ PNA probe (red). Sites of chromosome fusions are indicated by arrowheads, and TDMs are labeled by arrows. (Panels $a-c$ ) TDMs from three independently immortalized clones. (Panel $d$ ) TDM from V-sarcoma. $(D)$ Analysis of G-rich single-strand overhangs and telomere lengths from parental and immortalized clones at the indicated passages. A CHEF gel resolved digested DNAs, and in-gel hybridization with end-labeled (CCCTAA $)_{4}$ oligonucleotides was used to detect the 3' G-strand overhangs. The same gel was then denatured and hybridized with (TTAGGG) ${ }_{4}$ oligonucleotides to detect duplex telomeric DNA. Molecular weights of marker DNA are indicated.

$\mathrm{Wrn}^{-/-}$clones, in agreement with previously published results (Chang et al. 2003).

Notably, telomere FISH detected extra chromosomal telomeric signals in the metaphase spreads of all immortalized G5 $\mathrm{mTerc}^{-/-} \mathrm{Wrn}^{-/-}$cell lines at a frequency of $\sim 0.9$ per metaphase (Fig. 2C). Theses structures resemble double minute chromosomes (DMs), circular DNA elements that are frequently observed in genomically unstable cell lines undergoing drug selection. The DMs in our immortalized cell lines contained two telomeric signals that were of similar intensity to telomeres at the ends of chromosomes and bear striking resemblance to recently described telomeric DNA-containing DMs (TDMs), proposed to result from aberrant recombination events between telomeric sequences and chromosomeinternal telomeric repeats (Zhu et al. 2003). TDMs were not detected in parental G5 $\mathrm{mTerc}^{-/-} \mathrm{Wrn}^{-/-} \mathrm{MEFs}$, spontaneously immortalized G3 $\mathrm{mTerc}^{-/-} \mathrm{Wrn}^{-/-} \mathrm{MEFs}$ with competent telomeres, or immortalized G5 $\mathrm{mTerc}^{-/-}$ $\mathrm{Wrn}^{+/+} \mathrm{p} 53^{-/-}$cell lines (data not shown). These results raised the possibility that, in the setting of dysfunctional telomeres, loss of WRN may facilitate aberrant telomeric recombinations in immortalized G5 $\mathrm{mTerc}^{-/-}$ $\mathrm{Wrn}^{-/-}$cell lines, leading to the formation of TDMs.
Telomere sister chromatid exchange (T-SCE) is elevated in G5 $\mathrm{mTerc}^{-/-} \mathrm{Wrn}^{-/-}$cells

To assess whether telomeric recombination is elevated in immortalized G5 $\mathrm{mTerc}^{-/-} \mathrm{Wrn}^{-/-}$clones, we utilized chromosome orientation (CO)-FISH to assess the frequency of T-SCEs (Bailey et al. 2004). CO-FISH typically yields a characteristic pattern of two telomere signals, one on each end of the chromosome marking either lagging or leading strands, depending on the probe used for hybridization (Bailey et al. 2001). However, a T-SCE event within telomeric DNA splits the probe hybridization signal between the sister chromatids, creating a three-telomere (or four-telomere) hybridization pattern of signals that are often of unequal intensity (Fig. 3A). T-SCEs were rare in $\mathrm{mTerc}^{+/+} \mathrm{Wrn}^{+/-}$and parental G5 $\mathrm{mTerc}^{-/-} \mathrm{Wrn}^{+/-}$MEF controls (Fig. 3B,D). G3 mTerc ${ }^{-/-}$ $\mathrm{Wrn}^{-/-}$MEFs exhibited a twofold increase in the number of T-SCEs over controls, indicating that loss of WRN function may induce a low level of T-SCE in the setting of largely functional telomeres (Fig. 3D). Particularly noteworthy is the observation of a sixfold average increase in T-SCE levels in G5 $\mathrm{mTerc}^{-/-} \mathrm{Wrn}^{-/-}$parental cells (Fig. 3C,D, $p<0.05$ ), indicating a dual requirement 
Laud et al.

A

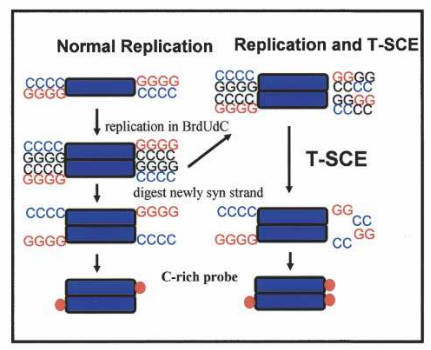

D

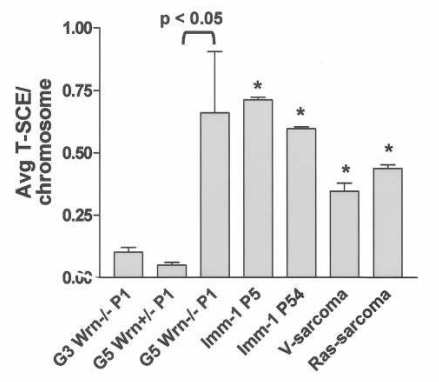

B

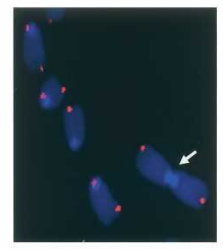

E

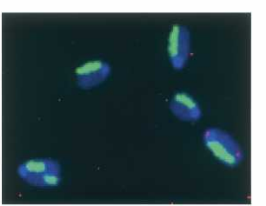

G

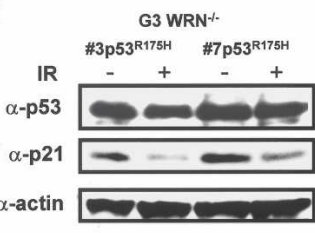

C

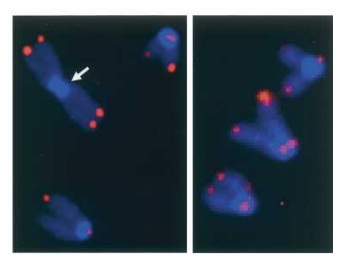

F

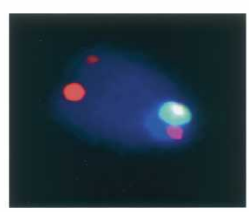

H

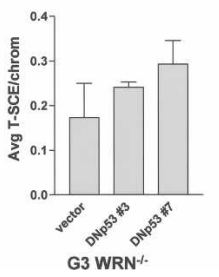

Figure 3. T-SCE is elevated in G5 $\mathrm{mTerc}^{-/-} \mathrm{Wrn}^{-/-}$cells. (A) Schematic of CO-FISH analysis (Bailey et al. 2004). (B) CO-FISH on G5 $\mathrm{mTerc}^{-/-} \mathrm{Wrn}^{+-}$MEFs reveals two characteristic CO-FISH telomere signals per chromosome. (C) CO-FISH of G5 mTerc ${ }^{-/-}$Wrn ${ }^{-/-}$ MEFs. T-SCEs are abundant, as exhibited by the split (double) telomere-signal hybridization patterns. Note Robertsonian translocation without telomere sequence at the point of fusion (arrowhead). (D) Quantification of the average number of T-SCEs per chromosome detected in cells of the indicated genotypes. Error bars represent standard error of the mean (SEM). Asterisk $\left({ }^{\star}\right)$ indicates a $p$ value of $<0.05$ (Student's $t$-test). (E) Genomic SCE in G5 $\mathrm{mTerc}^{-/-} \mathrm{Wrn}^{-/-}$MEFs. Harlequin anti-BrdU staining pattern after two rounds of incorporation reveals genomic SCE levels are not elevated. $(F)$ Dual labeling experiment: CO-FISH with telomere (T-SCEs, red signals) and mouse major satellite (single-sided, green signal) probes in G5 $\mathrm{mTerc}^{-1-} \mathrm{Wrn}^{-/-} \mathrm{MEFs}$; SCE within this highly repetitive block of pericentromeric repeats is not elevated. $(G)$ Reconstitution of mutant $\mathrm{p} 53^{\mathrm{R} 175 \mathrm{H}}$ activity in two independent G3 $\mathrm{mTerc}^{-/-}$Wrn ${ }^{-/-} \mathrm{MEF}^{-/ 2}$ clones. p53 and p21 levels were not elevated following 10 Gy IR treatment. (H) T-SCE levels in p53 ${ }^{\text {R175H }}$-immortalized G3 mTerc $^{-/-}$ $\mathrm{Wrn}^{-/-}$MEF clones. Error bars represent standard error of the mean (SEM). $p$ values indicate a lack of significance (Student's $t$-test).

for Wrn deficiency and telomere dysfunction in driving dramatically elevated T-SCE levels. These T-SCE rates remained elevated in all immortalized cell lines examined (Fig. 3D). Elevated recombination was specific to telomeric DNAs in G5 $\mathrm{mTerc}^{-/-} \mathrm{Wrn}^{-/-}$cells, as evidenced by background levels of SCEs not only in genomic DNA (Fig. 3E), but also in the mouse major satellite, highly repetitive blocks of pericentromeric repeat DNA (Fig. 3F). These results suggest that WRN normally functions to repress recombination specifically within telomeric DNA.

Because p53 can interact with telomeric DNA (Stansel et al. 2002; Razak et al. 2004) and suppresses homologous recombination in vivo (Bertrand et al. 1997; Mekeel et al. 1997; Lu et al. 2003), we asked whether the increase in T-SCE observed in immortalized cell lines was due at least in part to loss of p53 function. Introduction of a dominant-negative $p 53^{R 175 H}$ cDNA into two p53 wildtype G3 $\mathrm{mTerc}^{-/-} \mathrm{Wrn}^{-/-}$cell lines with background TSCE levels abrogated wild-type p53 function, as revealed by a lack of p21 induction following 10 Gy IR treatment (Fig. 3G) and subsequent cellular immortalization (data not shown). However, after analysis of 1085 metaphase spreads, we did not observe any significant increase in the number of T-SCEs in these cells (Fig. 3H). This result is in agreement with our observation that T-SCEs were highest in p53 competent G5 $\mathrm{mTerc}^{-/-} \mathrm{Wrn}^{-/-}$parental MEFs (Fig. 3D) and that T-SCEs were not elevated in several independent lines of p53-/- MEFs (Bailey et al. 2004). Thus, the elevated levels of T-SCEs observed in immortalized G5 $\mathrm{mTerc}^{-/-} \mathrm{Wrn}^{-/-}$cell lines were most likely due to the combined loss of WRN function and the presence of telomere dysfunction.

\section{Suppression of T-SCEs requires WRN helicase activity}

To further investigate the involvement of WRN in modulating T-SCE levels, we expressed cDNAs encoding wild-type human or mouse WRN in G5 $\mathrm{mTerc}^{-/-} \mathrm{Wrn}^{-/-}$ parental and immortalized cell lines (Fig. 4A,E). In contrast to vector-infected controls, reconstitution with either human or mouse WRN enabled early passage G5 $\mathrm{mTerc}^{-/-} \mathrm{Wrn}^{-/-}$MEFs to bypass premature replicative senescence and extended cellular lifespan by an additional 10 PDs (Fig. 4B). Importantly, sister telomere loss (STL), a characteristic of WS cells proposed to be due to an inability to efficiently replicate lagging strand telomeric DNA (Crabbe et al. 2004), was significantly re- 
A

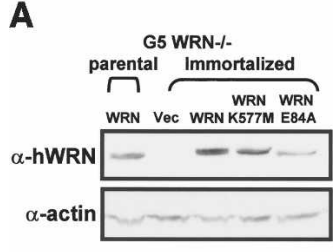

B
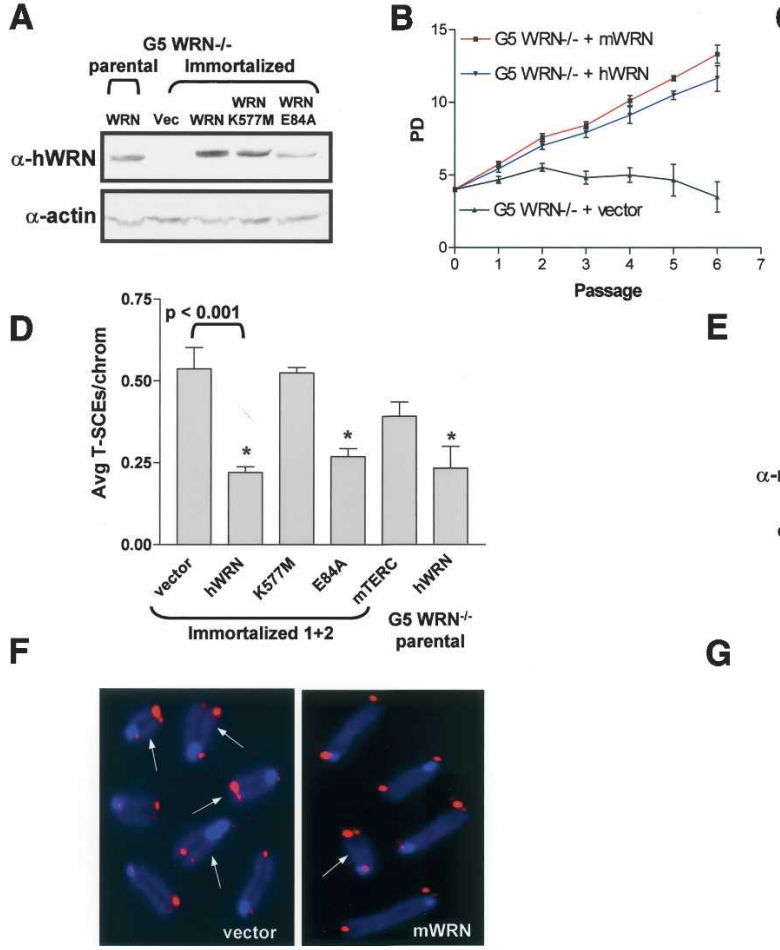

E
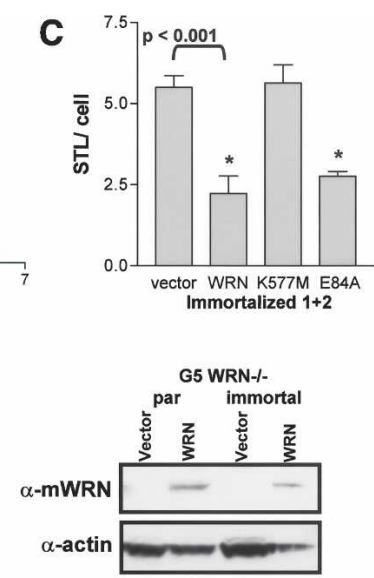

G

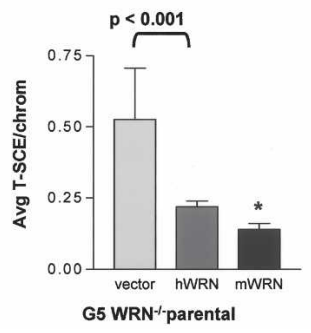

Figure 4. WRN helicase activity is required to suppress T-SCEs. (A) Western blot of G5 $\mathrm{mTerc}^{-/-} \mathrm{Wrn}^{-/-}$cell lines reconstituted with vector, human WRN, hWRN-K557M, and hWRN-E84A. Actin was used as loading control. (B) Wild-type mouse and human WRN, but not vector, rescues the growth defect observed in G5 $\mathrm{mTerc}^{-/-} \mathrm{Wrn}^{-/-}$MEFs. Error bars represent standard error of the mean (SEM). (C) Quantitation of STL in two immortalized cell lines reconstituted with vector, hWRN, hWRN-K557M, or hWRN-E84A. Error bars represent standard error of the mean (SEM). Asterisk $\left({ }^{\star}\right)$ indicates a $p$ value of $<0.001$ (Student's $t$-test). (D) Quantitation of T-SCE levels following reconstitution with the indicated proteins in either immortalized or parental G5 $\mathrm{mTerc}^{-/-} \mathrm{Wrn}^{-/-}$ MEFs. Error bars represent standard error of the mean (SEM). $\left(^{*}\right) p<0.001$ (Student's $t$ test). (E) Western blot of G5 $\mathrm{mTerc}^{-/-} \mathrm{Wrn}^{-/-}$ parental or immortalized cell lines with vector or mouse WRN. Actin was used as loading control. $(F)$ T-SCEs are reduced in mWRN, but not vector-reconstituted cell lines. (Arrows) Chromosomes containing TSCEs. $(G)$ Quantitation of reduction of T-SCE levels in G5 mTERC ${ }^{-/-} \mathrm{Wrn}^{-/-}$parental cell lines following reconstitution with mWRN. Error bars represent standard error of the mean (SEM). $\left(^{\star}\right) p<0.001$ (Student's $t$-test). duced in WRN, but not in vector-reconstituted G5 $\mathrm{mTerc}^{-/-} \mathrm{Wrn}^{-/-}$cells (Fig. 4C, $p<0.001$ ). In addition, the elevated number of DNA damage foci observed in G5 $\mathrm{mTerc}^{-/-} \mathrm{Wrn}^{-1-}$ MEFs (S. Chang et al. 2004) was reduced threefold in wild-type WRN, but not vector-reconstituted cell lines (data not shown). Taken together, these data show that reconstitution of WRN activity efficiently rescued many of the telomere-associated defects observed in G5 $\mathrm{mTerc}^{-/-} \mathrm{Wrn}^{-/-}$cells. Correspondingly, compared with two vector-transfected control cells, T-SCEs were reduced by $50 \%-70 \%(p<0.001)$ in two WRN reconstituted G5 $\mathrm{mTerc}^{-/-} \mathrm{Wrn}^{-/-}$parental and immortalized cell lines (Fig. 4D,F,G), consistent with the view that suppression of T-SCEs requires functional WRN activity. Interestingly, reconstitution of telomerase activity in two independent G5 $\mathrm{mTerc}^{-/-} \mathrm{Wrn}^{-/-} \mathrm{im}$ mortalized clones did not significantly alter the levels of T-SCE, suggesting that once T-SCE is engaged, it is not shut down by active telomerase (Fig. 4D).

To further substantiate that functional WRN is required to reduce T-SCE levels, we reconstituted two independent G5 mTerc ${ }^{-/-} \mathrm{Wrn}^{-/-}$cells with helicase-deficient WRN-K577M (Gray et al. 1997) and exonucleasedeficient WRN-E84A (Huang et al. 1998). Similar to wild-type WRN, expression of WRN-E84A resulted in a significant reduction in the number of T-SCEs observed (Fig. 4D, $p<0.001$ ), whereas expression of WRN-K577M failed to reduce T-SCE levels (Fig. 4D). Collectively, these data support the hypothesis that the WRN helicase activity is required to suppress recombination at telomeres.

\section{G5 $\mathrm{mTerc}^{-/-} \mathrm{Wrn}^{-/-}$cell lines are tumorigenic and engage the ALT pathway in vivo}

The known cancer-prone condition of WS patients and $\mathrm{mTerc}^{-/-} \mathrm{Wrn}^{-/-}$mice prompted us to determine the cancer implications of the enhanced immortalization potential and chromosomal instability observed in immortal G5 $\mathrm{mTerc}^{-/-} \mathrm{Wrn}^{-/-}$cell lines. In contrast to 0/16 tumors formed when parental G5 $\mathrm{mTerc}^{-/-} \mathrm{Wrn}^{-/-}$cells were injected subcutaneously into SCID mice, subcutaneous injection of $10 / 22{\mathrm{H}-\mathrm{Ras}^{\mathrm{V} 12}}$ transfected, immortalized G5 mTerc ${ }^{-/-}$Wrn $^{-/-}$clones (with loss of p53 function) into SCID mice generated highly malignant tumors (median latency $3.5 \mathrm{wk}$ ) (Fig. 5A, $p<0.01$; Table 1; Supplementary Fig. S2). Notably, 24/32 subcutaneous injections of vector-transfected, immortalized G5 $\mathrm{mTerc}^{-/-} \mathrm{Wrn}^{-/-}$clones also yielded aggressive tumors, but with a longer median latency of $\sim 6.3 \mathrm{wk}$ (Fig. 5A; Table $1, p<0.004)$. In contrast, injections of 12 spontaneously immortalized early passage G5 $\mathrm{mTerc}^{-/-}$ $\mathrm{Wrn}^{+/+} \mathrm{p} 53^{-/-}$MEFs did not produce any tumors in SCID mice within $20 \mathrm{wk}$ (Table 1). This result suggests that, in the setting of telomere dysfunction, p53 loss can cooperate with Wrn deficiency to promote tumorigenesis. However, it is also possible that the enhanced genomic instability observed in immortalized G5 $\mathrm{mTerc}^{-/-}$ 
A

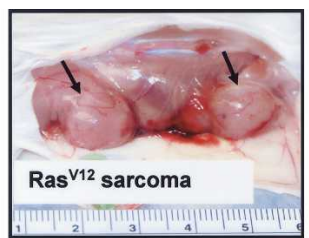

B
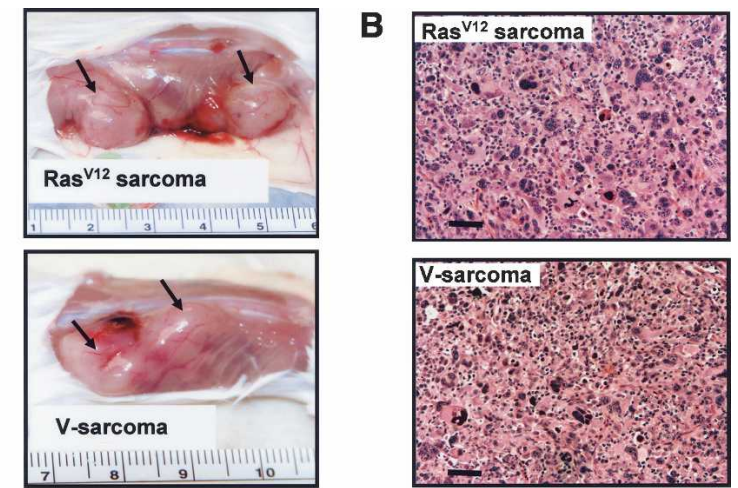

C

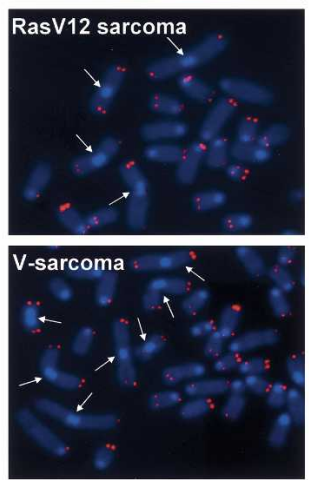

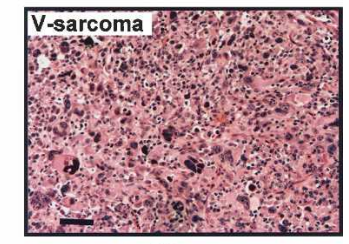

D
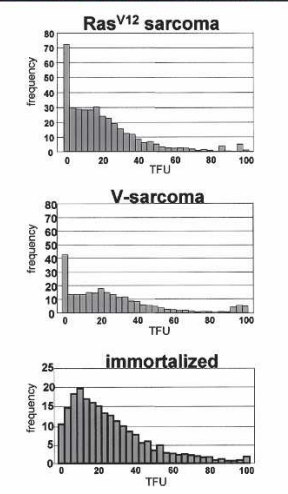

Figure 5. Transformation and tumorigenic potential of immortalized G5 $\mathrm{mTerc}^{-/-} \mathrm{Wrn}^{-/-}$MEFs. (A) Tumorigenicity of injected cell lines. pBabe-H-Ras ${ }^{\mathrm{V} 12}($ top $)$ and pBabe-vector transfected (bottom) immortalized MEFs were injected into flanks of SCID mice $\left(1 \times 10^{6}\right.$ cells per injection site). Arrows point to resultant tumors. (B) H\&E analysis of the tumors indicates that they are poorly differentiated sarcomas. $(C)$ Chromosomal aberrations in SCID tumors. Metaphase spreads from H-Ras ${ }^{\mathrm{V} 12}$ (top) and V-sarcoma (bottom), which were stained by DAPI (blue) and rhodamine-conjugated (CCCTAA) ${ }_{3}$ PNA probe (red). Fused chromosomes are indicated by arrows. (Y-axis) Frequency; ( $X$-axis) telomere fluorescence units (TFUs). (D) Telomere length analysis by Q-FISH in H-Ras ${ }^{\mathrm{V} 12}$ sarcoma (top), Vsarcoma (middle), and immortalized parental (bottom) cell lines.

$\mathrm{Wrn}^{-/-}$clones produced additional oncogenic insults that may help promote tumorigenesis. Histological analysis of both SCID tumor types revealed that they were well-differentiated sarcomas (hence designated Vsarcoma and $\mathrm{H}-\mathrm{Ras}^{\mathrm{V} 12}$-sarcoma) (Fig. 5B). Cytogenetic analysis revealed that both sarcomas possessed an increased number of chromosome fusions over injected parental cell lines (fourfold for V-sarcoma and sixfold for $\mathrm{H}-\mathrm{Ras}^{\mathrm{V} 12}$-sarcoma), documenting elevated genomic instability in these tumors (Fig. 5C). Quantitative telomere FISH (Q-FISH) analysis revealed a significant decrease in average telomere lengths in both tumor types compared with parental controls $160 \%$ for V-sarcoma, $45 \%$ for H-Ras ${ }^{\mathrm{V} 12}$-sarcoma $[p<0.05$ for both]) (Fig. 5D). While a fourfold to 6.8-fold increase in the number of telomere signal-free chromosome ends was detected in metaphase spreads from V-sarcomas and $\mathrm{H}$-Ras ${ }^{\mathrm{V} 12}$-sarcomas, a number of chromosomes with telomeres $5.3 \times$ to $8.5 \times$

longer than average was also observed (Fig. 5C,D). Analysis of telomere lengths by TRF Southern revealed that, in contrast to parental and injected immortalized cell lines, both $\mathrm{V}$-sarcomas and $\mathrm{H}-\mathrm{Ras}^{\mathrm{V} 12}$-sarcomas displayed a TRF pattern characteristic of human and mouse ALT cells (Fig. 6A; Yeager et al. 1999; Chang et al. 2003). In particular, telomere lengths were heterogeneous, ranging from $\sim 100$ to $8 \mathrm{~kb}$ in length. Size heterogeneity was also observed in the $3^{\prime}$ overhangs of the ALT cells (Fig. 6A). Elevated numbers of anaphase bridges, TDMs, and TSCEs were found in both tumors, suggesting ongoing telomeric recombination (Figs. 2B,C, 3D).

An additional characteristic of the ALT mechanism is the presence of ALT-associated promyelocytic leukemia bodies (APBs) in $5 \%$ of human ALT cells containing PML, TRF1, and other telomere-associated proteins including WRN (Yeager et al. 1999). Immunofluorescence analysis revealed that $\sim 5 \%-6 \%$ of two independently derived ALT V-sarcoma lines examined showed colocalization of TRF1 with PML in brightly staining large nuclear structures resembling APBs (Fig. 6B,C). This colocalization was not observed in parental and immortalized cell lines (Fig. 6B,C; data not shown). Reconstitution of telomerase activity in two independently derived ALT V-sarcoma cell lines did not reduce the number of APBs observed (Fig. 6C) nor did it affect the growth rates of these cells in vitro (data not shown). Taken together, these results suggest that under the biological pressure of tumorigenesis in vivo, the ALT pathway was activated in immortalized G5 $\mathrm{mTerc}^{-/-} \mathrm{Wrn}^{-/-}$clones in order to allow for subcutaneous tumor growth in SCID mice.

\section{Discussion}

The results presented here indicate that loss of WRN in the setting of telomere dysfunction promotes elevated recombination within telomeric DNA, escape from cellular senescence, and the emergence of immortalized clones that engage the ALT mechanism of telomere maintenance. It is important to note that unlike BLM deficiency, recombination resulting from WRN loss is observed specifically at telomeres and not at interstitial locations. Since reconstitution of WRN function in G5 $\mathrm{mTerc}^{-/-} \mathrm{Wrn}^{-/-}$cell lines readily suppressed T-SCE levels, we postulate that WRN normally represses inappropriate telomeric recombination intermediates and that the helicase domain is essential for this function. The highest rates of T-SCEs were found in presenescent G5 $\mathrm{mTerc}^{-/-} \mathrm{Wrn}^{-/-}$parental cell lines, and the parental cell line with the highest rate of T-SCEs also yielded the greatest number of immortalized clones. Since a single dysfunctional telomere can limit cellular survival in the absence of telomerase (Hemann et al. 2001), unequal TSCEs may confer a proliferative advantage to cells that stochastically acquire longer telomeres, enabling their escape from cellular senescence (Bailey et al. 2004). Unequal T-SCEs were frequently observed in immortalized G5 $\mathrm{mTerc}^{-/-} \mathrm{Wrn}^{-/-}$cell lines, which may explain why many chromosomes did not possess telomeric signals by 
Table 1. Summary of SCID mice subcutaneous tumor injection experiments

\begin{tabular}{|c|c|c|c|c|}
\hline Cell lines & $\begin{array}{l}\text { No. sites } \\
\text { injected }\end{array}$ & $\begin{array}{l}\text { No. tumors } \\
\text { formed }\end{array}$ & $\begin{array}{l}\text { Time to form tumors } \\
\text { to } 0.5 \mathrm{~cm} \text { size }\end{array}$ & Significance \\
\hline $\begin{array}{l}\text { Parental G5 m/Terc }{ }^{-/-} \mathrm{Wrn}^{-/-} \# 1 \text { P1 } \\
\text { Parental G5 m/Terc }{ }^{-/-} \mathrm{Wrn}^{-/-} \# 2 \text { P2 } \\
\text { Parental G5 m/Terc }{ }^{-/-} \mathrm{Wrn}^{-/-} \# 3 \text { P1 }\end{array}$ & $\begin{array}{l}4 \\
8 \\
4\end{array}$ & $\begin{array}{l}0 \\
0 \\
0\end{array}$ & n.a. & \\
\hline $\begin{array}{l}\text { Immortalized G5 m/Terc }{ }^{-/-} \mathrm{Wrn}^{-/-}+\text {vector \#1 P2 } \\
\text { Immortalized G5 m/ } \text { Terc }^{-/-} \mathrm{Wrn}^{-/-} \text {+ vector \#2 P2 } \\
\text { Immortalized G5 m/Terc }{ }^{-/-} \mathrm{Wrn}^{-/-} \text {+ vector \#3 P3 } \\
\text { Immortalized G5 m/ } / \mathrm{Terc}^{-/-} \mathrm{Wrn}^{-/-} \text {+ vector \#4 P5 }\end{array}$ & $\begin{array}{l}8 \\
8 \\
8 \\
8\end{array}$ & $\begin{array}{l}8 \\
6 \\
6 \\
4\end{array}$ & $\begin{array}{l}43 \mathrm{~d} \\
42 \mathrm{~d} \\
48 \mathrm{~d} \\
41 \mathrm{~d}\end{array}$ & \\
\hline $\begin{array}{l}\text { Immortalized G5 m/Terc }{ }^{-/-} \mathrm{Wrn}^{-/-}+\mathrm{H}-\mathrm{Ras} \text { \#1 P2 } \\
\text { Immortalized G5 m/Terc }{ }^{-/-} \mathrm{Wrn}^{-/-}+\mathrm{H}-\mathrm{Ras} \text { \#2 P2 } \\
\text { Immortalized G5 m/Terc }{ }^{-/-} \mathrm{Wrn}^{-/-}+\text {H-Ras \#3 P3 }\end{array}$ & $\begin{array}{l}4 \\
4 \\
4\end{array}$ & $\begin{array}{l}4 \\
2 \\
4\end{array}$ & $\begin{array}{l}25 \mathrm{~d} \\
26 \mathrm{~d} \\
20 \mathrm{~d}\end{array}$ & $P<0.004$ \\
\hline $\begin{array}{l}\text { Immortalized G5 m/Terc }{ }^{-/-} \mathrm{Wrn}^{++} \mathrm{p} 53^{-/-} \# 1 \mathrm{P} 3 \\
\text { Immortalized G5 m/Terc }{ }^{-/-} \mathrm{Wrn}^{++} \mathrm{p} 53^{-/-} \# 2 \text { P4 }\end{array}$ & $\begin{array}{l}4 \\
8\end{array}$ & $\begin{array}{l}0 \\
0\end{array}$ & n.a. & $P<0.01$ \\
\hline
\end{tabular}

(n.a.) Not applicable. $P$ values were determined by Wilcoxon two-sided ranks test analysis.

PNA-FISH, while others contained large tracks of telomeric repeats.

Although all immortalized clones examined exhibited robust T-SCEs, telomere length continued to decline, suggesting that elevated T-SCEs were insufficient to maintain overall telomere lengths. As telomeres continue to shorten, these cells will likely undergo growth arrest as they enter into crisis (Counter et al. 1992; Chang et al. 2003). When immortalized clones were injected subcutaneously into SCID mice, the strong selective pressure to maintain telomere length during crisis resulted in the rapid activation of the ALT pathway, as revealed by the characteristic telomere heterogeneity and presence of APML bodies. The observation that ag- gressive tumors formed in SCID mice as early as $\sim 3 \mathrm{wk}$ for H-Ras-transfected and $\sim 6$ wk for vector-transfected G5 $\mathrm{mTerc}^{-/-} \mathrm{Wrn}^{-/-}$cell lines favors the view that repair of dysfunctional telomeres by the ALT mechanism, and not the de novo acquisition of rare mutations, is the major contributor of tumor progression in vivo. We surmise that additional factors involved in modulating the ALT pathway are required for tumorigenesis. The telomerase-Werner compound knockout mouse thus offers a unique platform to discover novel genes involved in ALT activation during tumor formation. T-SCE levels in ALT tumor cell lines was not repressed when telomerase was expressed in these cells, consistent with previous observations indicating that once ALT is activated, it is not
A

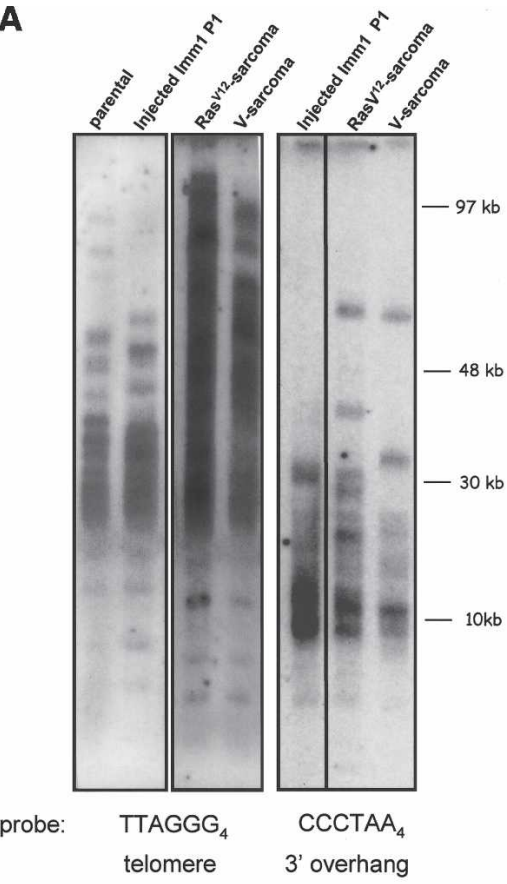

B

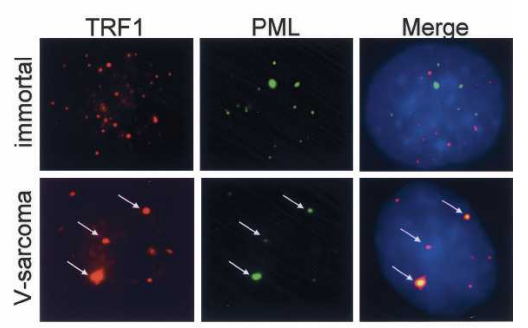

C

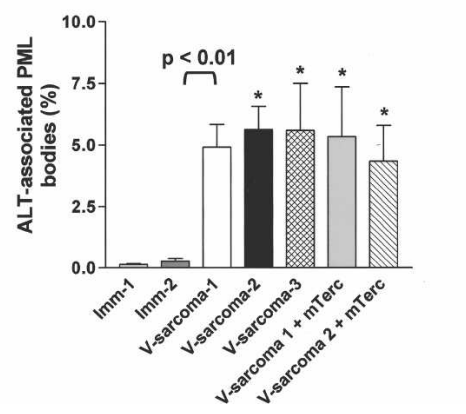

Figure 6. Engagement of the ALT pathway in $\mathrm{H}-\mathrm{Ras}^{\mathrm{V} 12}$ and V-sarcomas. (A) TRF Southern analysis for telomere lengths of indicated samples. End-labeled (TTAGGG) ${ }_{4}$ oligonucleotides were used to detect the $3^{\prime}$ G-strand overhangs, and duplex telomeric DNA was detected with end-labeled $(\text { CCCTAA })_{4}$ oligonucleotides. Note the increase in telomere length heterogeneity in both SCID tumor cell lines. (B) Colocalization of PML and TRF1 at telomeres. PML and TRF1 colocalized only in a subset of cells containing ALT foci (arrows). (C) Quantitation of ALT-associated PML bodies in the indicated cell types. Error bars represent standard error of the mean (SEM). $\left(^{\star}\right) p<0.01$. 
normally repressible by telomerase expression /Cerone et al. 2001; Perrem et al. 2001; Londono-Vallejo et al. 2004).

The finding that human ALT cell lines also display elevated T-SCEs (Bechter et al. 2004; Londono-Vallejo et al. 2004) suggests that aberrant homologous recombination (HR) at telomeres may be important for telomere length maintenance in these cells (Dunham et al. 2000). Recent observations that human ALT cells possess extrachromosomal telomere circles, most likely generated through HR (Cesare and Griffith 2004; Wang et al. 2004), and require the HR protein RAD51D for proper telomere maintenance (Tarsounas et al. 2004) further support this hypothesis. Our observation that TDMs and T-SCEs were prominent in immortalized G5 $\mathrm{mTerc}^{-/-} \mathrm{Wrn}^{-/-}$ cell lines suggests that acquisition of HR-mediated telomere recombination mechanisms may be an important prerequisite for transition to the ALT phenotype. TDMs are postulated to be the product of aberrant homologous recombination events between telomeres and chromosomal internal TTAGGG repeats sequences (Zhu et al. 2003), and our data suggest that WRN normally inhibits this activity. While the mechanism underlying T-SCEs has not been identified, our results suggest that lost of WRN function may be important for the initiation of aberrant/deregulated recombinations at telomeres. We have previously demonstrated that T-SCE is a reciprocal event; i.e., the G-rich and $\mathrm{C}$-rich telomere probes produce reciprocal CO-FISH patterns (Bailey et al. 2004). So, although SCE is generally believed to be a recombinational event, it is not typical in the general sense of commonly described models. One widely accepted aspect of SCE, however, is that it is associated with passage of the replication fork. T-SCEs may be triggered when a replication fork encounters a block in one of the parental template strands, leading to DNA polymerase stalling. This replication block may involve in vivo formation of G-quadruplexes, intramolecular structures containing G-quartets of four hydrogen-bonded guanines, on G-rich telomeric sequences (Schaffitzel et al. 2001; C.C. Chang et al. 2004; Granotier et al. 2005). WRN preferentially localizes to telomeres during the S-phase (Opresko et al. 2004; Crabbe et al. 2004) and can efficiently unwind Gquadruplexes in a helicase-dependent manner (Mohaghegh et al. 2001). We postulate that WRN normally resolves G-quadruplexes during DNA replication, allowing replication fork progression and complete synthesis of telomeric DNA. Lack of WRN helicase activity leads to replication fork stalling, resulting in loss of the lagging strand telomeric DNA (Crabbe et al. 2004) and elevated exchanges among sister telomeres. Along these lines, it is interesting to note the recently reported physical association between WRN and the single-stranded telomere-binding protein Pot1 (Opresko et al. 2005). Pot1 cooperates with WRN to efficiently unwind telomeric substrates, and Pot 1 can also disrupt G-quadruplexes, allowing telomerase to efficiently extend even these unfavorable substrates in vitro (Zaug et al. 2005). It is possible that both WRN and Pot1 cooperate to dissociate G-quadruplexes to facilitate telomere replication.
In summary, our results suggest that an increased propensity to escape cellular senescence due to elevated recombinations between sister telomeres may underlie the increased cancer incidence observed in WS patients. TSCEs may also facilitate the activation of the ALT pathway to promote cancer-relevant chromosomal aberrations and engender tumor formation. It will thus be informative to determine whether aberrant telomeric recombinations and activation of the ALT mechanism are present in tumors isolated from WS patients.

\section{Materials and methods}

Cell cultures, 3T3 assay, and TRF Southern analysis

Mouse embryonic fibroblasts (MEFs) were prepared from individual day $13.5 \mathrm{G} 3$ and G5 $\mathrm{mTerc}^{-/-} \mathrm{Wrn}^{-/-}, \mathrm{Wrn}^{+/+}$, and $\mathrm{Wrn}^{+/-}$ embryos. Six independently derived MEF cell lines of each genotype were used in all analyses. Serial passages of cell lines were performed according to the NIH3T3 protocol as described (Blasco et al. 1997). Cells at defined passages were harvested for chromosomal, TRF Southern, and Western analysis. TRF Southern analysis was performed as previously described (Chang et al. 2003).

Cytogenetics, Q-FISH, and SKY analysis

Metaphase chromosomes from MEFs were prepared as described (Chang et al. 2003) and subjected to Giemsa staining and/or FISH with Cy-3 labeled $\mathrm{T}_{2} \mathrm{AG}_{3}$ PNA probe. Q-FISH was performed as described (Baerlocher and Lansdorp 2004). Images were dark subtracted and flat fielded prior to quantitative analysis. SKY was performed according to manufacturer's recommendations using mouse chromosome paint probes (Applied Spectral Imaging). Depending on the quality of metaphase spreads, 10-20 metaphases from each sample were analyzed in detail.

\section{CO-FISH analysis}

CO-FISH has been described in detail previously (Bailey et al. 2001). Hybridization was performed with TRITC-OO-TTA GGGTTAGGGTTAGGG or FITC-OO-CCCTAACCCTAAC CCTAACCCA probes (Applied Biosystems). Fifteen to 25 metaphases/condition were scored blinded. Pairwise comparisons for statistical significance were made by Student's $t$-test. Differences between genetic backgrounds are considered significant only when $p$ values were $<0.05$.

\section{Immunofluoescence and Western blot analysis}

Cells were subjected to IF as described (Zhu et al. 2003). Primary antibodies used were rabbit anti-mouse TRF1 at 1:4000 (a kind gift from Dr. Jan Karlseder, Salk Institute, San Diego, CA) and mouse monoclonal anti-mouse PML at 1:500 (a kind gift from Dr. Kun Sang Chang, M.D. Anderson Cancer Center, Houston, TX). Secondary antibodies were anti-rabbit Alexa 488 and antimouse Alexa 595, both at 1:1000. The antibodies used for Western analyses were anti-mouse p53 (Pab 240, NeoMarkers; 1: 250), p19ARF (ab80-50, ABCAM; 1:250), p16 (M156SC, Santa Cruz; 1:200), p21 (SC-6246, Santa Cruz; 1:200), and $\gamma \mathrm{H} 2 \mathrm{AX}$ (AP132P, Upstate; 1:500). Anti-mouse actin (MAB1501, Chemicon; 1:20000) was used as a loading control. 
Reconstitution of telomerase activity in G5 $\mathrm{mTerc}^{-/-} \mathrm{Wrn}^{-/-}$ MEFs and TRAP assay

Immortalized cell lines were cotransfected with $20 \mu \mathrm{g}$ of mTerc plasmid DNA and $1 \mu \mathrm{g}$ pBabe-puro vector DNA and then selected with $4 \mu \mathrm{g} / \mathrm{mL}$ puromycin. Successful reconstitution was determined by telomerase activity via the TRAP assay (Oncor).

Reconstitution of telomerase activity in G5 $\mathrm{mTerc}^{-/-} \mathrm{Wrn}^{-/-}$ MEFs

Indicated cell lines were infected with full-length human WRN, K577M-WRN, and E84A-WRN cDNAs as previously described (Crabbe et al. 2004). Murine full-length WRN was subcloned into the pQCXIP retroviral vector (BD Biosciences) and used to infect MEF cell lines.

\section{Transformation assay and SCID tumor injections}

Early passage parental and immortalized G5 $\mathrm{mTerc}^{-/-} \mathrm{Wrn}^{-/-}$ MEFs, and p53 $172 \mathrm{P} / \mathrm{R} 172 \mathrm{P}$ MEFs were transfected with either pBabe vector DNA or pBabe-H-Ras as described (Liu et al. 2004). Transformed foci were quantitated by Giemsa staining and propagated into cell lines. SCID injections were performed as previously described (Chang et al. 2003). Tumors were monitored daily and mice sacrificed when tumors reached $1 \mathrm{~cm}$ in greatest dimension.

\section{Acknowledgments}

We are grateful to Leonard Guarente for the $\mathrm{Wrn}^{-/-}$mouse, to Edwin H. Goodwin for statistical analyses, to Tanner Hagelstrom for technical assistance, and to Jan Karlseder for providing WRN cDNA constructs. S.M.B was supported by NASA \#NNJ04HK83G. S.C. was supported by an Ellison New Scholars award, a Beeson Career Development award from the NIA/NIH, and generous support from the Abraham and Phyllis Katz Foundation. R.A.D. is an American Cancer Society Research Professor and an Ellison Medical Foundation Senior Scholar. This work was also supported by NIH grants R01CA84628 and U01CA84313.

\section{References}

Bailey, S.M., Cornforth, M.N., Kurimasa, A., Chen, D.J., and Goodwin, E.H. 2001. Strand-specific postreplicative processing of mammalian telomeres. Science 293: 2462-2465.

Bailey, S.M., Brenneman, M.A., and Goodwin, E.H. 2004. Frequent recombination in telomeric DNA may extend the proliferative life of telomerase-negative cells. Nucleic Acids Res. 32: 3743-3751.

Baerlocher, G.M. and Lansdorp, P.M. 2004. Telomere length measurements using fluorescence in situ hybridization and flow cytometry. Methods Cell Biol. 75: 719-750.

Bechter, O.E., Zou, Y., Walker, W., Wright, W.E., and Shay, J.W. 2004. Telomeric recombination in mismatch repair deficient human colon cancer cells after telomerase inhibition. Cancer Res. 64: 3444-3451.

Ben-Porath, I. and Weinberg, R.A. 2004. When cells get stressed: An integrative view of cellular senescence. J. Clin. Invest. 113: $8-13$.

Bertrand, P., Rouillard, D., Boulet, A., Levalois, C., Soussi, T., and Lopez, B.S. 1997. Increase of spontaneous intrachromosomal homologous recombination in mammalian cells expressing a mutant p53 protein. Oncogene 14: 1117-1122.
Blasco, M.A. 2002. Telomerase beyond telomeres. Nat. Rev. Cancer 2: 627-633.

Blasco, M.A., Lee, H.W., Hande, M.P., Samper, E., Lansdorp, P.M., DePinho, R.A., and Greider, C.W. 1997. Telomere shortening and tumor formation by mouse cells lacking telomerase RNA. Cell 91: 25-34.

Cerone, M.A., Londono-Vallejo, J.A., and Bacchetti, S. 2001. Telomere maintenance by telomerase and by recombination can coexist in human cells. Hum. Mol. Genet. 10: 19451952.

Cesare, A.J. and Griffith, J.D. 2004. Telomeric DNA in ALT cells is characterized by free telomeric circles and heterogeneous t-loops. Mol. Cell. Biol. 24: 9948-9957.

Chang, S., Khoo, C., Naylor, M., Maser, R., and DePinho, R.A. 2003. Telomere-based crisis: Functional differences between telomerase activation and ALT in tumor progression. Genes \& Dev. 17: 88-100.

Chang, C-C., Kuo, I.C., Ling, I.F., Chen, C.T., Chen, H.C., Lou, P.J., Lin, J.J., and Chang T.A. 2004. Detection of quadruplex DNA structures in human telomeres by a fluorescent carbazole derivative. Anal. Chem. 76: 4490-4494.

Chang, S., Multani, A.S., Cabrera, N.G., Naylor, M.L., Laud, P., Lombard, D., Pathak, S., Guarente, L., and DePinho, R.A. 2004. Essential role of limiting telomeres in the pathogenesis of Werner syndrome. Nat. Genet. 36: 877-882.

Counter, C.M., Avilion, A.A., LeFeuvre, C.E., Stewart, N.G., Greider, C.W., Harley, C.B., and Bacchetti, S. 1992. Telomere shortening associated with chromosome instability is arrested in immortal cells which express telomerase activity. EMBO J. 11: 1921-1929.

Crabbe, L., Verdun, R.E., Haggblom, C.I., and Karlseder, J. 2004. Defective telomere lagging strand synthesis in cells lacking WRN helicase activity. Science 306: 1951-1953.

Du, X., Shen, J., Kugan, N., Furth, E., Lombard, D., Cheung, C., Pak, S., Luo, G., Pignolo, R., DePinho, R.A., et al. 2004. Telomere shortening exposes functions for the Werner and Bloom syndrome genes in mice. Mol. Cell. Biol. 24: 84378446.

Dunham, M.A., Neumann, A.A., Fasching C.L., and Reddel, R.R. 2000. Telomere maintenance by recombination in human cells. Nat. Genet. 26: 447-450.

Faragher, R.G., Kill, I.R., Hunter, J.A., Pope, F.M., Tannock, C., and Shall, S. 1993. The gene responsible for Werner syndrome may be a cell division 'counting' gene. Proc. Natl. Acad. Sci. 90: 12030-12034.

Granotier, C., Pennarun, G., Riou, L., Hoffschir, F., Gauthier, L.R., De Cian, A., Gomez, D., Mandine, E., Riou, J.F., Mergny, J.-L., et al. 2005. Preferential binding of a G-quadruplex ligand to human chromosome ends. Nucleic Acids Res. 33: 4182-4190.

Gray, M.D., Shen, J.C., Kamath-Loeb, A.S., Blank, A., Sopher, B.L., Martin, G.M., Oshima, J., and Loeb, L.A. 1997. The Werner syndrome protein is a DNA helicase. Nat. Genet. 17: 100-103.

Hemann, M.T., Strong, M.A., Hao, L.Y., and Greider, C.W. 2001. The shortest telomere, not average telomere length, is critical for cell viability and chromosome stability. Cell 107: 67-77.

Hickson, I. D. 2003. RecQ helicases: Caretakers of the genome. Nat. Rev. Cancer 3: 169-178.

Huang, S., Li, B., Gray, M.D., Oshima, J., Mian, S.I., and Campisi, J. 1998. The premature ageing syndrome protein, WRN, is a $3^{\prime} \rightarrow 5^{\prime}$ exonuclease. Nat. Genet. 20: 114-116.

Johnson, F.B., Marciniak, R.A., McVey, M., Stewart, S.A., Hahn, C.W., and Guarente, L. 2001. The Saccharomyces cerevisiae WRN homolog Sgs 1 participates in telomere maintenance in 
cells lacking telomerase. EMBO J. 20: 905-913.

Kamijo, T., Zindy, F., Roussel, M.F., Quelle, D.E., Downing, J.R., Ashmun, R.A., Grosveld, G., and Sherr, C.J. 1997. Tumor suppression at the mouse INK4a locus mediated by the alternative reading frame product p19ARF. Cell 91: 649-659.

Liu, G., Parant, J.M., Lang, G., Chau, P., Chavez-Reyes, A., ElNaggar, A.K., Multani, A., Chang, S., and Lozano, G. 2004. Chromosome stability, in the absence of apoptosis, is critical for suppression of tumorigenesis in Trp53 mutant mice. Nat. Genet. 36: 63-68.

Lombard, D.B., Beard, C., Johnson, B., Marciniak, R.A., Dausman, J., Bronson, R., Buhlmann, J.E., Lipman R., Curry, R., Sharpe, A., et al. 2000. Mutations in the WRN gene in mice accelerate mortality in a p53-null background. Mol. Cell. Biol. 20: 3286-3291.

Londono-Vallejo, J.A., Der-Sarkissian, H., Cazes, L., Bacchetti, S., and Reddel, R.R. 2004. Alternative lengthening of telomeres is characterized by high rates of telomeric exchange. Cancer Res. 64: 2324-2327.

Lu, X., Lozano, G., and Donehower, L.A. 2003. Activities of wildtype and mutant p53 in suppression of homologous recombination as measured by a retroviral vector system. Mutat. Res. 522: 69-83.

Martin, G.M. and Oshima, J. 2000. Lessons from human progeroid syndromes. Nature 408: 263-266.

Maser, R.S. and DePinho, R.A. 2002. Connecting chromosomes, crisis, and cancer. Science 297: 565-569.

Mekeel, K.L., Tang, W., Kachnic, L.A., Luo, C.M., DeFrank, J.S., and Powell, S.N. 1997. Inactivation of p53 results in high rates of homologous recombination. Oncogene 14: 18471857.

Melcher, R., von Golitschek., R., Steinlein, C., Schindler, D., Neitzel, H., Kainer, K., Schmid, M., and Hoehn, H. 2000. Spectral karyotyping of Werner syndrome fibroblast cultures. Cytogenet. Cell Genet. 91: 180-185.

Mohaghegh, P., Karow, J.K., Brosh Jr., R.M., Bohr, V.A. and Hickson, I. D. 2001. The Bloom's and Werner's syndrome proteins are DNA structure-specific helicases. Nucleic Acids Res. 29: 2843-2849.

Myung, K., Datta, A., Chen, C., and Kolodner, R.D. 2001. SGS1, the Saccharomyces cerevisiae homologue of BLM and WRN, suppresses genome instability and homeologous recombination. Nat. Genet. 27: 113-116.

Opresko, P.L., Otterlei, M., Graakjaer, J., Bruheim, P., Dawut, L., Kolvraa, S., May, A., Seidman, M.M., and Bohr V.A. 2004. The Werner syndrome helicase and exonuclease cooperate to resolve telomeric $\mathrm{D}$ loops in a manner regulated by TRF1 and TRF2. Mol. Cell. 14: 763-774.

Opresko, P.L., Mason, P.A., Podell, E.R., Lei, M., Hickson, I.D., Cech, T.R., and Bohr, V.A. 2005. POT1 stimulates recQ helicases WRN and BLM to unwind telomeric DNA substrates. J. Biol. Chem. 280: 32069-32080. [Epub July 18, 2005.]

Perrem, K., Colgin, L.M., Neumann, A.A., Yeager, T.R., and Reddel, R.R. 2001. Coexistence of alternative lengthening of telomeres and telomerase in hTERT-transfected GM847 cells. Mol. Cell. Biol. 21: 3862-3875.

Prince, P.R., Emond, M.J., and Monnat Jr., R.J. 2001. Loss of Werner syndrome protein function promotes aberrant mitotic recombination. Genes \& Dev. 15: 933-938.

Quelle, D.E., Ashmun, R.A., Hannon, G.J., Rehberger, P.A., Trono, D., Richter, K.H., Walker, C., Beach, D., Sherr, C.J., and Serrano, M. 1995. Cloning and characterization of murine p16INK4a and p15INK4b genes. Oncogene 11: 635-645.

Razak, Z.R., Varkonyi, R.J., Kulp-McEliece, M., Caslini, C., Testa, J.R., Murphy, M.E., and Broccoli, D. 2004. p53 differentially inhibits cell growth depending on the mechanism of telomere maintenance. Mol. Cell. Biol. 24: 5967-5977.

Romanov, S.R., Kozakiewicz, B.K., Holst, C.R., Stampfer, M.R., Haupt, L.M., and Tlsty, T.D. 2001. Normal human mammary epithelial cells spontaneously escape senescence and acquire genomic changes. Nature 409: 633-637.

Salk, D., Au, K., Hoehn, H., and Martin, G.M. 1981. Cytogenetics of Werner's syndrome cultured skin fibroblasts: Variegated translocation mosaicism. Cytogenet. Cell Genet. 30: 92-107.

Schaffitzel, C., Berger, I., Postberg, J. Hanes, J., Lipps, H.J., and Plückthun, A. 2001. In vitro generated antibodies specific for telomeric guanine-quadruplex DNA react with Stylonychia lemnae macronuclei. Proc. Nat1. Acad. Sci. 98: 8572-8577.

Smogorzewska, A. and de Lange, T. 2004. Regulation of telomerase by telomeric proteins. Annu. Rev. Biochem. 73: 177208 .

Stansel, R.M., Subramanian, D., and Griffith, J.D. 2002. p53 binds telomeric single strand overhangs and t-loop junctions in vitro. J. Biol. Chem. 277: 11625-11628.

Tarsounas, M., Muñoz, P., Claas, A., Smiraldo, P.G., Pittman, D. L., Blasco, M.A., and West, S.C. 2004. Telomere maintenance requires the RAD51D recombination/repair protein. Cell 117: 337-347.

Wang, R.C., Smogorzewska, A., and de Lange, T. 2004. Homologous recombination generates T-loop-sized deletions at human telomeres. Cell 119: 355-368.

Wyllie, F.S., Jones, C.J., Skinner, J.W., Haughton, M.F., Wallis, C., Wynford-Thomas, D., Faragher, R.G., and Kipling, D. 2000. Telomerase prevents the accelerated cell ageing of Werner syndrome fibroblasts. Nat. Genet. 24: 16-17.

Yamagata, K., Kato, J., Shimamoto, A., Goto, M., Furuichi, Y., and Ikeda, H. 1998. Bloom's and Werner's syndrome genes suppress hyperrecombination in yeast sgs1 mutant: Implication for genomic instability in human diseases. Proc. Nat1. Acad. Sci. 95: 8733-8738.

Yeager, T.R., Neumann, A.A., Englezou, A., Huschtscha, L.I., Noble, J.R., and Reddel, R.R. 1999. Telomerase-negative immortalized human cells contain a novel type of promyelocytic leukemia (PML) body. Cancer Res. 59: 4175-4179.

Zaug, A.J., Podell, E.R., and Cech, T.R. 2005. Human POT1 disrupts telomeric G-quadruplexes allowing telomerase extension in vitro. Proc. Natl. Acad. Sci. 102: 10864-10869. [Epub July 25, 2005.]

Zhu, X.D., Niedernhofer, L., Kuster, B., Mann, M., Hoeijmakers, J.H., and de Lange, T. 2003. ERCC1/XPF removes the 3 ' overhang from uncapped telomeres and represses formation of telomeric DNA-containing double minute chromosomes. Mol. Cell 12: 1489-1498. 


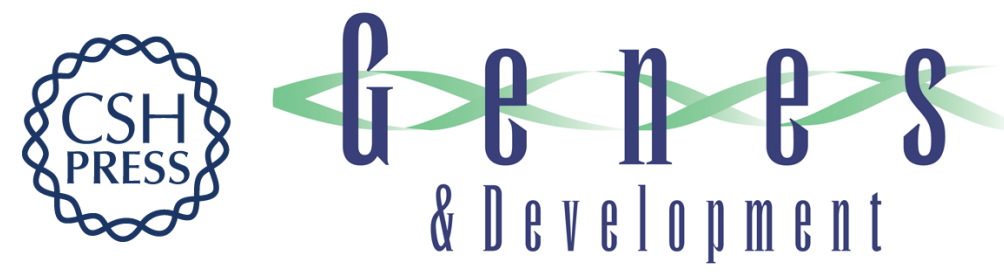

\section{Elevated telomere-telomere recombination in WRN-deficient, telomere dysfunctional cells promotes escape from senescence and engagement of the ALT pathway}

Purnima R. Laud, Asha S. Multani, Susan M. Bailey, et al.

Genes Dev. 2005, 19:

Access the most recent version at doi:10.1101/gad.1321305

Supplemental http://genesdev.cshlp.org/content/suppl/2005/10/20/19.21.2560.DC1

Material

References This article cites 53 articles, 20 of which can be accessed free at:

http://genesdev.cshlp.org/content/19/21/2560.full.html\#ref-list-1

License

Email Alerting Receive free email alerts when new articles cite this article - sign up in the box at the top

Service right corner of the article or click here.

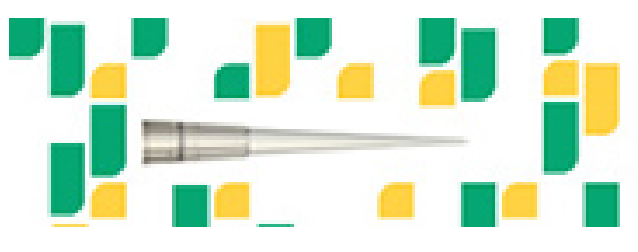

Focused on your science. 